ARTICLE

https://doi.org/10.1057/s41599-019-0345-3

\title{
What's new from the zoo? An analysis of ten years of zoo-themed research output
}

\author{
Paul E. Rose (10 ${ }^{1,2 \star}$, James E. Brereton (10) ${ }^{3}$, Lewis J. Rowden ${ }^{4}$, Ricardo Lemos de Figueiredo ${ }^{5}$ \& Lisa M. Riley ${ }^{6}$
}

\begin{abstract}
The modern zoo's roles command empirical enquiry to determine the effectiveness of zoos locally and globally. Ten years ago, published work identified the need for empirical research on a diverse range of species beyond charismatic zoo megafauna. We review zoo-based research published in the decade since this original recommendation. We collectively evaluate zoo-themed research papers from those working in zoos and those external to zoos but studying zoo-housed animals. By systematically searching Web of Science ${ }^{(}$for zoo-based research and performing inductive content analysis to code year, journal, study animal's taxonomic classification, and research aims and outputs we evaluate trends in zoo-themed research, contrasted with trends in species holding. Significantly more birds and fish are kept compared to mammals, reptiles and amphibians, but mammals are consistently the primary research focus. Whilst output generally rises, only for birds is a steady increase in publications apparent. Husbandry evaluation is a major aim/output, but papers on pure biology, cognition and health also feature. Most publications lead to "specific advancement of knowledge" including validation of methodologies. We show that: (1) trends in species holdings are unrelated to trends in publication; (2) zoo-themed research makes meaningful contributions to science; (3) zoo researchers should diversify their aim/output categories and chosen study species to close the persisting research gaps that we have identified. Finally, we discuss our findings in the context of evident species biases within research outputs across the broader fields of zoology, conservation and ecology.
\end{abstract}

\footnotetext{
${ }^{1}$ Centre for Research in Animal Behaviour, College of Life and Environmental Sciences, Washington Singer Labs, University of Exeter, Perry Road, Devon, Exeter EX4 4QG, UK. ${ }^{2}$ WWT, Slimbridge Wetland Centre, Slimbridge, Gloucestershire GL2 7BT, UK. ${ }^{3}$ University Centre Sparsholt, Sparsholt College Hampshire, Sparsholt, Winchester, Hampshire SO21 2NF, UK. ${ }^{4}$ Zoological Society of London, London Zoo, Outer Circle, Regent's Park, London NW1 4RY, UK. ${ }^{5}$ School of Biosciences, University of Birmingham, Edgbaston, Birmingham B15 2TT, UK. ${ }^{6}$ Centre for Animal Welfare, Faculty of Health and Wellbeing, University of Winchester, Winchester, Hampshire SO22 4NR, UK. *email: p.rose@exeter.ac.uk
} 


\section{Introduction}

oos and aquariums have the potential to be excellent locations to develop, implement and complete scientific research. Zoo populations enable hypothesis-driven questions to be answered on species/topics that would be challenging in the wild. This is evidenced by, for example, ground-breaking insights into the reproductive biology of the critically endangered Sumatran rhinoceros, Dicerorhinus sumatrensis (Roth et al., 2004) or results on the energetic costs of locomotion in bears, Ursidae (Pagano et al., 2018). Zoological databases that hold information on species' biology can enhance the scientific literature on natural history and ecology (Conde et al., 2019); information that also informs animal management practices and species conservation strategies both in-situ and ex-situ. As centres for both pure and applied science, the output from zoological collections not only covers a range of disciplines (Loh et al. 2018) but is of increasing value to multiple stakeholders working in all parts of the world with all taxonomic groups.

The four aims of the modern zoo-conservation, education, research and recreation (Mason, 2007, Fernandez et al., 2009) provide a framework for scientific investigation. The importance of research to the modern zoo is reflected in the number of pieces of national zoo legislation that require research activities to be conducted (Hosey et al., 2009). Conversely, entertainment is perceived as the least important role of the zoo (Reade and Waran, 1996), yet visitation must be maintained as zoos can be reliant on entrance fees for income. This income provides a means for zoos to fulfil their roles in conservation and education, hence zoos must remain attractive destinations to visit (Bueddefeld and Van Winkle, 2018). Research into the educational role of the zoo has scrutinised the effectiveness of zoos as learning environments (Marino et al., 2010, Dawson and Jensen, 2011, Moss and Esson, 2013). Despite an increase in zoo visitor studies over the past decade (Jensen, 2010, Moss and Esson, 2010), there is little evidence that zoos promote understanding or proconservation behaviour. The importance of robust experimental design and application of "good science" is also evident in literature (Wagoner and Jensen, 2010, Moss et al., 2017) promoting the need for an evidence-based approach.

Such an evidence-based approach extends to animal husbandry, central to which is researching animal behaviour. A majority of zoo scientific studies has previously been shown to be of a behavioural nature (Hosey, 1997). The relevance of behavioural science to conservation outcomes was postulated by Sutherland (1998) who states the importance of conserving behaviour as part of conservation objectives. A potential fifth aim of the zoo, to promote excellence in animal welfare (Fernandez et al., 2009) further supports the need to increase the amount of scientific study and application of such study, into zoo animal management. An increasingly ethically-aware public, who focus on the importance of good welfare and are not just concerned with animal cruelty (Whitham and Wielebnowski, 2013) emphasises the need for zoos to manage their populations to ensure a high quality of life can be attained and maintained for all individuals.

As scientific research that collects data to answer an hypothesis-driven question is key to ensuring husbandry regimes are most appropriate, zoos have invested in collaboration with academics (Fernandez and Timberlake, 2008), in the development of research methodologies (Plowman, 2003, Plowman, 2008) and in the creation of research-focussed committees and working groups (BIAZA, 2018b) to increase and develop their scientific output and its uptake by zoological collections. By expanding on how empirical research is applied within zoological collections (e.g., to husbandry routines, visitor engagement and interpretation objectives, or population management goals) the reach, impact and outcome of each of the zoo's aims is strengthened.
With a new focus on collection planning for population sustainability (Traylor-Holzer et al., 2019), a paucity of scientific research for many familiar (i.e., commonly-kept, often-seen-inthe-zoo) species has been apparent (Melfi, 2009). This paper (Melfi, 2009) shows that researchers study a limited number of individuals of high-profile, charismatic species-a trend previously noted in the wider field of "wildlife research" (Bautista and Pantoja, 2005). Species less appealing to the public but housed in greater numbers across more zoological collections have been ignored. Likewise, when considering species responses to captivity, mammals are often focal subjects (Clubb and Mason, 2003) and ecological data are used to inform our understanding of their responses to captivity (Mason, 2010, Kroshko et al., 2016). However, for other non-mammalian taxa we consider how they cope with the human-created environment of the zoo less often (Carere et al., 2011). Species with a long history of captivity, well-known and recognisable to the visiting public can still challenge us regarding their optimal captive care (Hatt et al., 2005, Rose, 2018) and empirical, structured research programmes can help redress the balance between what a species needs to thrive and what is provided for survival in the zoo. Therefore, to move forward with species-specific Best Practice (husbandry) Guidelines (EAZA, 2019) less considered taxa, common but "ignored" species or animals perceived as less charismatic, e.g., reptiles, amphibians, fish and invertebrates, (BIAZA, 2018a) need to be the focus of future research attention. Melfi (2009) highlights this lack of research into non-mammals as the cause of anecdote or "rules of thumb" methods of providing captive care.

As such, the aim of our paper was to look retrospectively from 2009 to 2018 to see how much more scientific research has been conducted into the areas identified by Melfi (2009) as lacking a research focus. Specifically, we collected research papers from five different taxonomic groups, to evaluate the range of taxa now included in scientific publications and we investigated if/how uptake and output of evidence, useful for management, has diversified. We used Melfi (2009)'s Table 1 (page 581) and Fig. 2 (page 582) as a guide to what constitutes "forgotten taxa"focussing on those animals with large populations but limited scientific investigation. We have added invertebrates, amphibians and fish to our analysis that were excluded or not fully included in the original Melfi paper for reasons outlined below. Melfi (2009)'s Fig. 2 shows the relationship between the number of individuals of specific animal species held by British and Irish association (BIAZA) zoos, as well as the number of zoos that hold each represented species, compared to the number of projects conducted on these species, based on records from the BIAZA research database. A bias towards the study of a small number of charismatic mammalian species, for example chimpanzees (Pan troglyodytes), bonobos (P. paniscus), orangutans (Pongo sp.), elephants (Elephas maximus, Loxodonta africana), is clear from this figure. Melfi notes that more projects between 1998 and 2008 were conducted on the two species of Pan compared to all projects on birds, reptiles, amphibians, fish and invertebrates in this sample of BIAZA institutions-90 against 84 studies. We aim to see if such a bias exists in a sample of wider zoo output in the ten years from this dataset being published.

\section{Methods}

Papers were collected using the bibliographic database Web of Science $\odot$. Key term searches were carried out by including zoo $^{\star}$ combined with either behaviour ${ }^{\star} /$ behavior $^{\star}$ or welfare or nutrition and research for each type of taxa (mammal, bird, reptile, amphibian, fish), for example "zoo* bird behaviour*. Each author was assigned a specific taxon and asked to scrutinise search 
results in the same manner, inputting data into a standardised spreadsheet. In January 2019, the lead author searched for remaining papers in 2018 across all taxa and terms to complete the dataset. Papers were categorised by year, species (and later class, genus and order), aim and main output. Aim was defined as the reason why the research was conducted (e.g., to determine the effect of a change of husbandry routine, or the influence of enrichment on behaviour, or to benchmark positive indicators of welfare). Output was defined as the key finding of the study and how this helps to underpin evidence-based zoo management.

Papers that covered more than one species of the same taxa (e.g., free-flight aviaries) were categorised as "multiple mixed". Papers that covered a range of species from different taxa (e.g., visitor studies research or research into common patterns of stereotypic behaviours) were categorised as "multiple taxa review". Papers that detailed methodological advances or novel approaches to data collection were categorised as "theory". Papers that focussed on people including where data could add information on best practice animal care (e.g., influences on collection planning based on visitor perception) were categorised as "visitor". Only peer-reviewed scientific papers in the Web of Science(C) search were included. Conference papers were not counted. In total, 1063 papers were categorised from 236 publications.

The impact factor of each publication was recorded from the individual journal website or from www.bioxbio.com if the impact factor was not clear on the journal's homepage.

Rationalising aims and outputs from each article. Using content analysis, two authors (PER and LMR) coded the description of a paper's aim and outcome into an aim class and an outcome class and outcome gain (see Table 1 for explanation). Papers were checked at the original source if both reviewing authors (during coding) were unsure of the aims and outcomes of the paper from its abstract. Aims were prioritised based on the paper's own statement of their original aim and not on subsidiary findings. The aim "Husbandry and training" also includes papers that investigated visitor effects because visitors are provided in the zoo whether the animal wants them or not and therefore they directly impact on daily husbandry and management decisions. For each paper, one author stated their interpretation of aim and outcome code and this was judged using a protocol (Table 1) by the second author who also ensured the first aim/outcome was prioritised. Triangulation was not necessary as the two authors agreed on $100 \%$ of codes. Codes were created using an inductive approach. If a new aim/outcome was coded or new example were added, all previously papers in that aim class, outcome class or output gain were re-coded to reduce bias.

Specialised journals and global species holding. To compare any trend in publication output seen in the main Web of Science ${ }^{\circledR}$ dataset with two specialist zoo journals that are i) an annual publication without an impact factor and ii) have only incomplete listing on this database, an analysis of the output from the International Zoo Yearbook, IZYB, (published annually since 1960 by the Zoological Society of London) and the new openaccess Journal of Zoo and Aquarium Research, JZAR, (published by the European Association of Zoos and Aquaria, EAZA) was conducted in the same manner (assessing the number of publications per taxa between 2009 and 2018). From these two journals, 354 papers were collected.

\section{Table 1 Explanatory codes and examples of classifying aims, outcomes, and gains into specific categories}

\begin{tabular}{|c|c|c|}
\hline Aim classes & Outcome classes & Outcome gains \\
\hline Behaviour & Animal and ecosystem health & Advancing knowledge \\
\hline $\begin{array}{l}\text {-e.g., time-activity budgets, } \\
\text { ethograms }\end{array}$ & $\begin{array}{l}\text {-e.g., successful treatment of } X \text { disease or improved } \\
\text { environmental quality }\end{array}$ & $\begin{array}{l}\text {-Specific (e.g., application to an individual species or } \\
\text { behaviour) }\end{array}$ \\
\hline Cognition & Behaviour change (human) & -General (e.g., wide-spread application across taxa) \\
\hline $\begin{array}{l}\text {-e.g., problem solving and } \\
\text { learning. }\end{array}$ & $\begin{array}{l}\text {-e.g., Measurable influences on attitudes towards } \\
\text { conservation work }\end{array}$ & $\begin{array}{l}\text { Advancing practical application } \\
\text {-Specific (e.g., development of a species-specific } \\
\text { husbandry guideline) }\end{array}$ \\
\hline $\begin{array}{l}\text { Conservation and breeding } \\
\text { programmes }\end{array}$ & Conservation and sustainability & $\begin{array}{l}\text {-General (e.g., application of positive welfare } \\
\text { indicators for all fish) }\end{array}$ \\
\hline -e.g., EEP or SSP initiatives & $\begin{array}{l}\text {-e.g., improved population viability or successful } \\
\text { increases in reproductive rate }\end{array}$ & $\begin{array}{l}\text { Data deficient (more research needed) } \\
\text {-e.g., no conclusive support for hypotheses or lack }\end{array}$ \\
\hline Husbandry and training & Husbandry and welfare & of relationship between variables \\
\hline $\begin{array}{l}\text {-e.g., development of best } \\
\text { practice guides }\end{array}$ & $\begin{array}{l}\text {-e.g., husbandry can be improved based on the results } \\
\text { from research }\end{array}$ & \\
\hline Methods & Pure biology & \\
\hline $\begin{array}{l}\text {-e.g., how to collect } X \text { data in } Y \\
\text { situation }\end{array}$ & -e.g., "blue sky" results that add to subject knowledge & \\
\hline Nutrition & Scientific validity & \\
\hline $\begin{array}{l}\text {-e.g., diet survey and nutritional } \\
\text { analysis }\end{array}$ & $\begin{array}{l}\text {-e.g., demonstrate the efficacy and relevance of a } \\
\text { method or way of collecting data }\end{array}$ & \\
\hline \multicolumn{3}{|l|}{$\begin{array}{l}\text { Physiology and reproductive } \\
\text { technologies }\end{array}$} \\
\hline \multicolumn{3}{|l|}{-e.g., endocrinology studies } \\
\hline \multicolumn{3}{|l|}{$\begin{array}{l}\text { Veterinary medicine and } \\
\text { animal health }\end{array}$} \\
\hline \multicolumn{3}{|l|}{-e.g., advances in treatment } \\
\hline \multicolumn{3}{|l|}{ Visitor studies } \\
\hline \multicolumn{3}{|l|}{$\begin{array}{l}\text {-e.g., how do zoo guests view } \\
\text { animals? }\end{array}$} \\
\hline \multicolumn{3}{|l|}{ Welfare } \\
\hline $\begin{array}{l}\text {-e.g., enrichment, quality of life } \\
\text { assessment }\end{array}$ & & \\
\hline
\end{tabular}




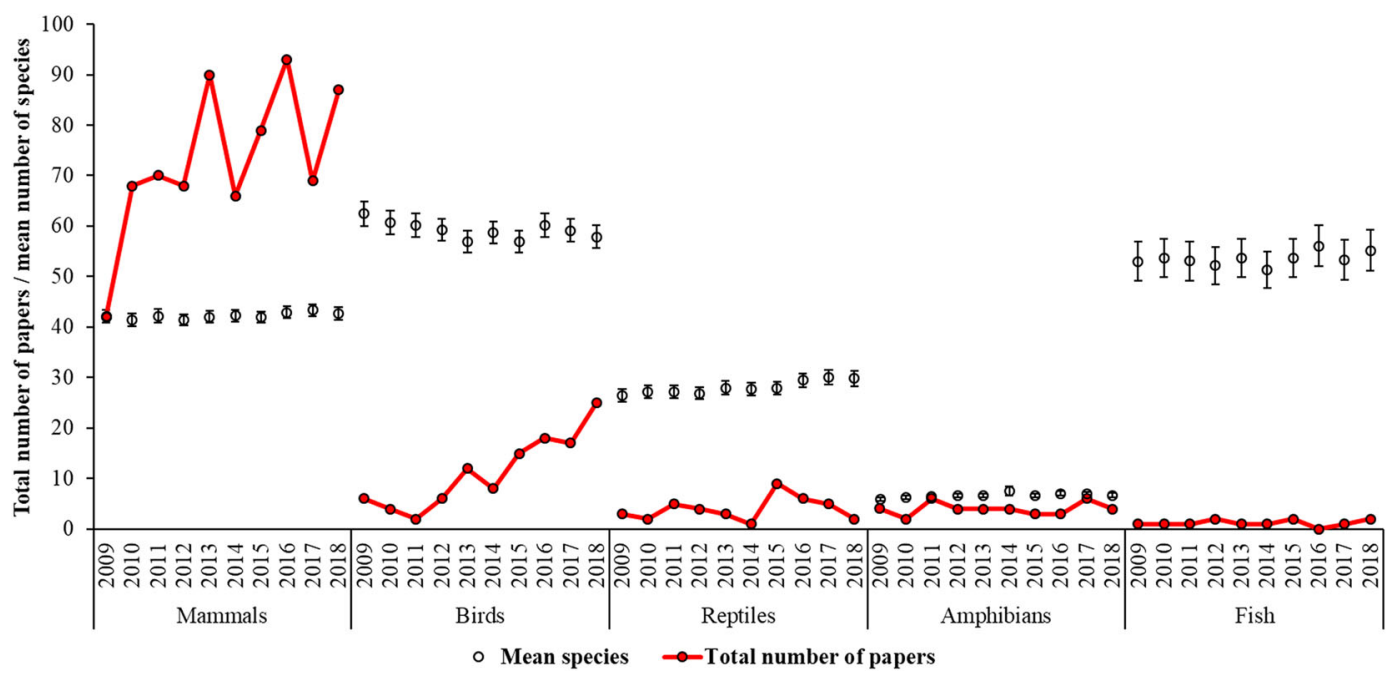

Fig. 1 The mean number of species within each taxonomic class (white dot, no line) housed globally in zoological establishments that provided data to the International Zoo Yearbook from 2009 to 2018 compared to the number of publications (red dot, red line), per year, for that taxonomic class. Overall birds are the most speciose taxonomic class housed by zoos globally and show the biggest increase in research output

To provide context to research output gathered from searching for numbers of papers on specific taxa, data on species holdings of all zoos globally, published in the International Zoo Yearbook, were analysed alongside of the research-focussed data. These (unpublished) species holdings data were collected as part of an on-going additional research project (by author JEB) with the annual number of each species of mammal, bird, reptile, amphibian and fish kept at each zoo being recorded.

Invertebrates. Papers on zoo-applicable invertebrate research were sampled alongside of the main dataset. As we were keen to follow Melfi (2009)'s categories of research subjects as closely as possible and because of the high number of papers to review between authors, details collected on invertebrate papers were restricted to: the name of the journal and year, the type of aim of the paper and the study subject. Again, only papers found in Web of Science ${ }^{\odot}$ were recorded and the same categories for searching across the complete database were used: e.g., "zoo* invertebrate OR cephalopod OR arachnid welfare". Abstracts of papers were read to ensure there was an application to zoo populations- i.e., the paper was not solely focussed on laboratory experimentation. A total of 17 papers were identified from 2011 to 2018 across 12 different publications.

Total sample size. Overall, 1434 zoo-focussed research papers were collected for analysis and evaluation (from the main dataset, from the IZYB and JZAR dataset, and for the separate search for invertebrate-specific research).

Data analysis. Data were analysed in R studio v. 1.0.136 (R Core Team, 2016). Where required, data were checked for collinearity using the "car package" (Fox and Weisberg, 2011), with values $<2$ taken as acceptable. Plots of residuals in R for each model were used to assess the distribution of data before further testing.

To compare differences between total counts of mammalian, avian and fish species held, a two-sample $t$-test was run. To determine any change in the number of species in each class housed by global zoos over the course of the study, a one-way ANOVA was run for species counts against year.

To compare the number of papers published against the taxonomic class of species held plus year of publication, a general liner model was run in $\mathrm{R}$ and post-hoc testing to ascertain differences between predictors was run using the "pbkrtest" and "Ismeans" packages for R studio (Halekoh and Højsgaard, 2014, Lenth, 2016).

Fitted models were also run in $\mathrm{R}$, with associated linear regression plots, for each outcome, gain and taxonomic class per year to identify any significant trend in the number of papers published on that theme.

For those papers with a focus on one taxonomic class only $(n=863)$, a multinomial logistic regression was run in R studio using "multinom" function from the package "nnet" (Venables and Ripley, 2002). The "AER" (Kleiber and Zeileis, 2008) and "afex" (Singmann et al., 2019) packages were used to generate $P$ values of the model fit from ANOVA and Wald's tests. Post-hoc testing was run using the "lsmeans" package (Lenth, 2016) using (model, pairwise $\sim$ factor | object, adjust = "tukey", mode $=$ "prob") to generate $P$ values for each pair of factors for each outcome across taxonomic class.

A linear regression was run in $\mathrm{R}$ with follow-up ANOVA analysis of the fitted model to determine the significance of predictors (taxonomic class, aim, outcome, gain and year of publication) on journal impact factor.

To remove any chances of Type 1 error, the Benjamini and Hochberg (1995) method of correcting the level of significance was employed when comparing multiple $P$ values.

\section{Results}

Global species holdings and the taxonomic focus of research papers. Figure 1 shows that birds and fish are the most speciose taxa housed in zoos globally, and amphibians comprise the fewest number of species housed. Significantly fewer species of mammal are housed compared to birds $(t=-21.07 ; \mathrm{df}=11896 ; P<0.001)$ and fish $(t=-8.86 ; \mathrm{df}=9291 ; P<0.001)$. For each taxonomic class, there was no significant change in the number of species held by zoos globally between 2009 and 2018 (mammals $P=0.985$; birds $P=0.809$; reptiles $P=0.488$; amphibians $P=0.559$; fish $=0.999$ ).

There is a significant relationship between the number of papers published on each taxonomic class, the year of publication and the mean number of species in that class held $\left(F_{14,35}=58.59\right.$; $\left.r^{2}=0.94 ; P<0.001\right)$. Across years the increase in the number of papers published for all taxonomic classes combined was not statistically significant (regression slope $=7.41 ; \quad P=0.338$ ), 
suggesting that the overall number of papers on all topics identified from this literature search remains similar.

Significant differences are noted for the output for mammals against reptiles (higher number of mammalian papers), for fish against mammals (lower number of fish papers) and for amphibians against mammals (lower number of amphibian papers), Table S1 (supplementary information). When evaluating the interaction between species held and taxonomic class (species_holding*taxonomic_class) there is no significant relationship, showing that the average number of each species (in each taxonomic class) held in zoos is not influencing the number of publications on these taxa (intercept $=1.16, P=0.976$ ) even though the relationship between the overall number of papers published and taxonomic class of animal is still significant $\left(\mathrm{F}_{9,40}=74.65 ; r^{2}=93 \% ; P<0.001\right)$. As there is no significant change in the number of species held over this time period, an increase in the holdings of one class is not causing an increase in research output in that specific class.

Trends in the specific categories and aims of zoo-based papers. Analysis reveals that most of the papers have a husbandry and/or welfare focus (see Table S2, supplementary information), be that in the aim $(n=301)$ of the paper or the overall outcome $(n=435)$. The high number of papers coded as a pure biology outcome $(n=271)$ shows that zoos can be centres for the advancement of "blue sky" science, as well as for applied science. This idea is supported by the proportion of papers (75\%) that add to our knowledge of the species or topics being investigated. With only $1.7 \%$ of papers having no specific gain (i.e., a need for more research to answer the paper's aim) zoo-based papers are clearly able to impact on knowledge and practice in this area of science.

Is there a relationship between the question being asked and what type of animal is being studied?. The Analysis of Deviance (type II) tests from the model showed that a paper's aim (likelihood ratio $\chi^{2}=81.65 ; \mathrm{df}=36 ; P<0.001$ ), outcome (likelihood ratio $\chi^{2}=54.23 ; \mathrm{df}=20 ; P<0.001$ ) and gain (likelihood ratio $\left.\chi^{2}=30.13 ; \mathrm{df}=16 ; P=0.017\right)$ are all significant predictors of the taxonomic class of the paper. Year was not a significant predictor but may be trending in that direction (likelihood ratio $\chi^{2}=49.97$; $\mathrm{df}=36 ; P=0.06$ ). Post-hoc comparison of outcomes for each taxonomic class identified multiple significant predictors (for example Table S3, supplementary information).

Surveying across single-taxonomic class papers only (for the aim, outcome and gain of each paper) shows differences in the proportion of papers on each specific theme by taxa. For fish, $43 \%$ of papers had a husbandry aim, 57\% of fish papers had a pure biology outcome and $71 \%$ of fish papers were identified as having a gain of a specific advancement in knowledge.

Across those papers on reptiles, $45 \%$ had a veterinary medicine and animal health aim, $42 \%$ had an animal and ecosystem health outcome, and $52 \%$ of papers had a gain of a specific advancement in knowledge. For amphibians, $16 \%$ of papers had a behavioural aim and $16 \%$ had a veterinary medicine and animal health aim, $29 \%$ of amphibian papers had a husbandry outcome and $48 \%$ paper were identified as providing a gain by specifically advancing knowledge.

An aim of behaviour was identified for $31 \%$ of all papers focussing on birds, $39 \%$ of bird papers had a husbandry and welfare outcome and $69 \%$ of bird papers provided a gain of a specific advancement in knowledge. For papers on mammals, $32 \%$ had a husbandry and training aim, $43 \%$ had a pure biology outcome, and $70 \%$ provided a gain in the specific advancement of knowledge.
For those wishing to advance an evidence-basis for zoo animal husbandry, $23 \%$ of all papers provided a gain of how to advance practice (either species-specific or general) with $78 \%$ of these being on mammals. Most papers focussed on adding to our knowledge of the study subject(s). Table S4 (supplementary information) further evidences the popularity of specific taxonomic orders as subjects for zoo-themed research by illustrating the types of question asked and output gained on the different taxonomic classes identified in our dataset. Details are provided for the top five orders from mammals, birds and amphibians, for all three orders of reptiles and for all six orders of fish from the ten-year dataset. Bias in the questions being asked at a taxonomic level is evident for each order and may relate to the accessibility of this animal in a zoo or the expertise of the researcher conducting the science.

Predicting future trends. Assessing the main dataset $(n=1063)$ for increases or decreases in the number of publications per theme or on a particular taxonomic group type of animal identifies key areas where zoo research is growing in output. A significant relationship is found for the number of papers published on captive birds over the ten-year period, +3.5 papers/year $\left(F_{1,8}=26.99 ; r^{2}=74.3 ; P=0.001\right)$, supporting the trend illustrated by Fig. 1. Papers with an overall methodology aim also increase, +1.01 papers/year, indicating that zoological research is continuing to publish new ways of assessing the animals within collections $\left(F_{1,8}=30.23 ; r^{2}=76.5 ; P=0.001\right)$. Papers with an aim of veterinary medicine and animal health also increase $\left(+1.01\right.$ articles per year) significantly $\left(F_{1,8}=8.97 ; r^{2}=47.0 \%\right.$; $P=0.017)$. Figure $S 1$ (supplementary information) illustrates these trends over time.

There are also increases on year for outcome with 1.12 extra papers per year published on animal and ecosystem health $\left(F_{1,8}=9.69 ; r^{2}=49.1 \% ; P=0.014\right)$. Output of papers with a visitor studies aim was not significant $(P=0.08,+0.2$ papers/ year). Husbandry and welfare outcome papers may tend towards a significant increase of +1.7 papers/year $(P=0.062)$. This general trend is supported by Fig. S1, which shows a rise in this outcome category over time (although this is not consistent from one year to the next). Finally, there is a significant increase $(+5.8$ papers/year) in the number of papers published that specifically advance our knowledge of zoo animals $\left(F_{1,8}=38.18 ; r^{2}=80.5 \%\right.$; $P<0.001)$.

Conservation and population sustainability papers and those focussing on human behaviour change outcomes appear low overall, when compared to those on pure biology and on husbandry (Fig. S1). Such information highlights areas for research to expand into in the future to ensure output continues to be novel and relevant.

Patterns of publication from an annual and a new scientific journal. To compare with output taken from the impact factorlisted publications in the main dataset, Fig. S2, supplementary information, shows the publication trend for the IZYB and for JZAR. Trends in the IZYB data are harder to predict, even though overall the number of mammal-focussed papers is higher than for other classes (47\% overall). However, a notable pattern of mammal-focussed publication is evident in each year of JZAR; since its first publication in $2013,59 \%$ of papers are on mammals. All single-class taxonomic categories aside from mammals can be absent from each of these two publications (Fig. S2). Therefore, consideration for the theme of each volume or the breadth of papers included within may be needed to ensure that a widerange of species are focussed on per edition. 

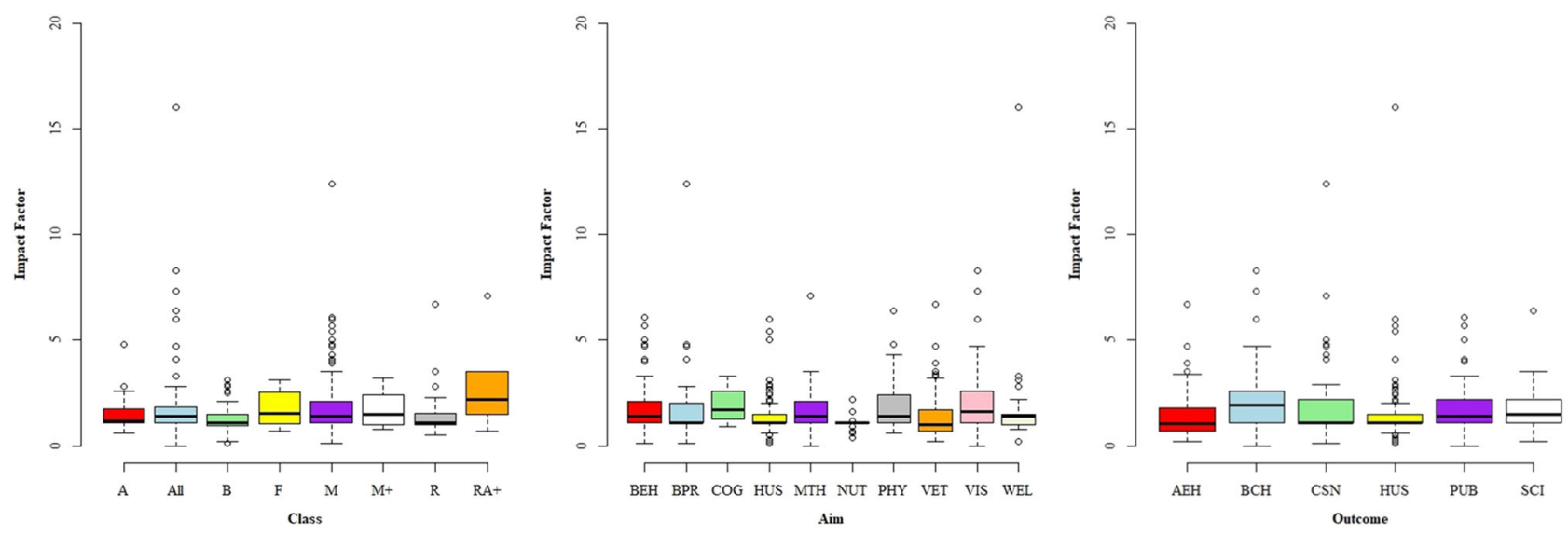

Fig. 2 Boxplots to show the median impact factor of papers for each type of animal or research aim. Top: taxonomic class (A amphibians, All All classes included, B birds, F fish, M mammals, M+ Mammals plus another taxa, R Reptiles, RA+ Reptiles and amphibians plus another taxa). Middle: Aim category (BEH Behaviour, BPR Breeding programmes, HUS husbandry and training, MTH methods, NUT nutrition, PHY physiology, VET veterinary medicine and animal health, VIS visitor studies, WEL welfare). Bottom: Outcome category (AEH animal and ecosystem health, BCH behaviour change human, CSN conservation and sustainability, HUS husbandry and welfare, PUB pure biology, $\mathrm{SCl}$ scientific validity). Papers covering all taxa show the largest range in impact and the highest impact overall

Assessing impact. Differences are apparent in the spread of journal impact factors for where papers on each class of animal and each type of research topic are published (Fig. 2). The top five highest impact factor journals include research on multiple taxonomic classes and papers that provide a general advancement in knowledge (with one species-specific focus (elephants) that provides a specific advancement in knowledge). Of the 1063 papers from 2009-2018, two are published in journals with an impact factor of above 10, with the majority (75\%) published in journals with an impact factor of below 2 .

Papers with Husbandry and welfare, Human behaviour change, and Conservation and sustainability outcomes are published in the highest impact journals. Papers with a Welfare, Visitor studies, Methods, and Husbandry aim are also found in these higher-impact publications. It is exciting to see that a wide range of topics can be published and disseminated widely across the breadth of the scientific literature- zoo-focussed research is not restricted to "zoo only" journals.

There is a significant relationship between several predictors and publication in a higher impact factors journal $\left(F_{34,1028}=2.59\right.$; $\left.r^{2}=5 \% ; P<0.001\right)$. Taxonomic class $(P<0.001)$, aim $(P<0.001)$ and outcome $(P=0.009)$ are all significant predictors of publication in a journal with a higher impact factor. Year of publication $(P=0.36)$ or gain $(0.994)$ show no relationship to a journal's impact factor. Model estimates for individual GLMs show significantly higher impact factor journals contain papers covering both reptiles and amphibians (estimate $=1.32$, $P=0.007)$ and papers on birds were more likely to be published in lower impact factor journals compared to other taxonomic groups (estimate $=-0.57 ; P<0.001$ ).

For the aim of the paper, those on nutrition (estimate $=-0.49$; $P=0.012$ ) and veterinary medicine/animal health (estimate $=$ $-0.33 ; P=0.006$ ) were published in lower impact journals, whereas those on visitor studies were significantly more likely to be found in higher impact publications (estimate $=0.52$; $P=0.002$ ). When assessing each paper's outcomes, those relating to human behaviour change were more likely to be published in journals with higher impact factors (estimate $=0.94 ; P<0.001$ ) compared to other outcome categories.

Comparing the interaction between taxonomic class and the paper's aim $\left(F_{61,1001}=1.85 ; r^{2}=5 \% ; P<0.001\right)$ shows that higher impact journals are successfully chosen for physiology papers that cover all classes (estimate $=2.36 ; P=0.04$ ) and for methods papers published on reptiles and amphibians (estimate $=3.06$; $P=0.05)$. A significant interaction is present for papers on reptiles and amphibians with conservation/sustainability outcomes $\quad$ (estimate $=4.47 ; \quad P=0.001$ ), model summary $F_{39,1023}=3.003 ; r^{2}=7 \% ; P<0.001$. No significant relationship is noted for any interaction between the paper's gain and the taxonomic class used as the subject, and choice of higher impact journals.

What about invertebrates?. For the 17 relevant papers obtained on invertebrates, the highest number $(n=11,65 \%)$ focussed on reviewing or providing commentary on, across taxa, bigger questions relating to welfare (including a paper on enrichment practices that covered other taxa as well invertebrates to determine preferences for a specific type of enrichment provided and a paper on how to design judgement bias tasks, both of which have important welfare connotations). Papers on cephalopods and those covering a review of invertebrate taxa as part of a wider question (e.g., enrichment or welfare assessment) made up several of the articles recorded ( $n=5,29 \%$, respectively). Invertebrates articles could cover pure science (i.e., personality studies), as well as be used to inform the management of other taxa in the zoo (i.e., investigating food supplements for invertebrates that are then used as foods for other species). The median impact factor was 1.5, similar to output presented for other taxa in Fig. 2. Papers published in the top-five impact factor journals were two articles that reviewed welfare (published in journals with an impact factor of 16), a cephalopod welfare paper (published in a journal with an impact factor of 5.23) and paper on cephalopod personality (in a journal with an impact factor of 4.13) and a review paper on welfare (in a journal with an impact factor of 3 ).

\section{Discussion}

Our results show that zoo-themed researchers are increasing their research output year-on-year; Fig. 1 illustrates that, for bird research at least, the overall trend in output is positive. A bias in the study of large charismatic mammals dominates the overall number of papers published, but zoo-themed researchers are investigating a wide array of topics and increasing their output into areas of knowledge gain, as well as practical application (Fig. S1, supplementary information). This mammal bias appears similar to that noted in the wider field of zoology (Bautista and 
Pantoja, 2005) and the need for a more informed approach (such as our call for more scientific investigation for taxon-specific husbandry guides) is echoed by previous research that highlights a lack of scientific rigour within strategies implemented for habitat and wildlife conservation (Reichhardt, 1999).

Zoo-themed research output appears to be aligning with wider conservation messages, for example as emphasised by the One Plan Approach (CBSG, 2015), as well as with moves to encourage more direct pro-environmental human behaviour change (Smith et al., 2008, Spooner et al., 2019) and wider usage of ecological evidence for the development of species-specific management plans (EAZA, 2019). We demonstrate that zoo-themed research output can cross academic boundaries and answer big questions that extend far beyond the animals housed at the zoo themselves. Increases in the number of papers adding to knowledge of species biology shows the wider relevance of zoos to "blue sky" science and an impact across different fields for all taxa investigated (Fig. 2). This expanding and considered research output appears to align with developments noted in other areas of biology too- for example the relative success of conservation initiatives in the United States (Schwartz, 2008) even though data to underpin these measures can often be lacking.

The focus on specific taxonomic groups compared to others (Table S1) may be a facet of the particular research interest of individual scientists, the commonality of a particular species in the zoo, or the availability of species in zoos close to the workplace of scientists that are publishing in this field. There are clear trends in the choice of taxonomic order when looking over the aims, outcomes and gains from research published on zoo-housed animals (Table S3), indicating that researchers opt for a particular taxonomic order as a study system when designing how to test an experimental hypothesis. A Husbandry and training aim and a Husbandry and welfare outcome predominates in this dataset (Table S2) showing that zoo research is focussing on key areas of management to improve captive care. This illustrates that the majority of these papers are adding to knowledge to strengthen the aims of the modern zoo, and it is encouraging that only 18 papers provided no firm conclusion to their way. Those researching the zoo are clearly able, in the vast majority of cases, to provide an answer to their question.

Our results identify some interesting trends in how zoo animals are used for research. Notably that reptiles feature more in veterinary and health-related papers than other taxonomic classes, yet whilst mammals are the most commonly studied class (Fig. 1), they show the least variation in research aim for across all classes (Table S3), with papers asking either behavioural or husbandry and training related questions. Amphibians are the class with the most diverse array of questions asked-covering breeding, husbandry, nutrition, physiology, behaviour, and veterinary medicine and animal health. This suggests that the conservation relevance of amphibians in zoos (Zippel et al., 2011) and the urgency by which captive-naive populations have had to be created suddenly ex situ (Pavajeau et al., 2008) has created niches for variation in research questions more quickly than in mammal populations, for example, that have not been exposed to sudden changes in the novelty of species held.

We identify papers that cover each of the four roles of the modern zoo, demonstrating that zoos are prepared to research how well they are meeting their goals and be scrutinised on the outputs from such research. Given calls for good welfare to be a fifth aim of the modern zoo (Fernandez et al., 2009), the high number of papers with a full or in-part welfare outcome $(41 \%$ of all identified papers) is encouraging. Welfare science is moving quickly, with novel approaches validated (Williams et al., 2018, Richter and Hintze, 2019, Yon et al., 2019) and an increasing use of natural ecology information as a keystone in determining the relevance of husbandry in the zoo (Rose, 2018). Therefore, the application of animal-based welfare assessment to ensure individual welfare is good, rather than a completely resource-based approach is a key area of research for zoos to focus upon (Whitham and Wielebnowski, 2013). And as 74\% of identified papers that had either a specific or general advancement in practice $(n=245)$ were fully or partly focussed on a welfare outcome, zoos are forging ahead to evaluate many aspects of welfare of the animals they house. Our results indicate this is not confined to a single taxon but relevant to all investigated except reptiles where focus is on health and conservation. This may be because so little of the wild biology is known for many reptilian species that, when in captivity, immediate threats to survival (e.g., disease) must be the primary research concern. Whatever the underlying reason, here there is an identifiable opportunity for future zoo research.

Three key gaps in knowledge of zoo animal management were identified by Melfi (2009). Firstly, that research tended to investigate indicators of poor rather than positive welfare. Change is evident with research assessing animal-based indicators of a good quality of life now being published (Williams et al., 2018, Yon et al., 2019), and methods for positive welfare assessment for zoo invertebrates, as well as an evidence-basis for captive invertebrate care (Bethell, 2015, Tonkins et al., 2015) can also be found. We demonstrate that targeted research, evidenced by the year-on-year increase in bird research output (for example), with popular aims of husbandry and welfare and with an advancing knowledge outcome, means all aspects of welfare are being considered and investigated.

Secondly that housing and husbandry are historically based on anecdote or tradition. A scientific approach to inform husbandry is noticeable in our dataset, with housing style (Rowden and Rose, 2016), daily husbandry regimes (Rose et al., 2016), nutrition (Gussek et al., 2018), enrichment practices (Costa et al., 2018), breeding recommendations (Asa et al., 2011) and animal health measures (Greenwell and Montrose, 2017) being based on evidence gathered to determine optimal care. The asking of numerous questions (Table S4) with an amphibian model shows that zoo researchers are considering key knowledge gaps at different taxonomic levels when constructing an experimental design. Even within a taxonomic group bias persists as certain species (e.g., Pan spp. in the Primate order) command the evidence-based approach. This is not to say zoos specifically ignore other species as a myriad reasons may explain why the husbandry practices of one species are more science-led than another (for example, the number of individuals kept in zoos). And as Pan sp. studies continue to demonstrate, many research projects are required before an holistic approach to husbandry (and welfare generally) can be achieved. Our paper shows that for many species, zoo research is the start of this evidence-gathering journey.

Thirdly, a lack of species-specific biological data may be inhibiting zoo research output. Well-studied animals, such as Pan sp., will continue to receive research interest because scientists have a reliable bank of background information to utilise. Consequently, equally important research candidates remain understudied due to this lack of baseline information. Use of ecological information on species' habitat choices can be used to inform housing (Mason, 2015, Kroshko et al., 2016, Mellor et al., 2018) and suitability of husbandry can be evaluated via individual preference testing (Mehrkam and Dorey, 2015, Troxell-Smith et al., 2017a, TroxellSmith et al., 2017b). Therefore, constructing "in-zoo" questions based on manipulations that can yield species-specific information means that these poorly understood species can be researched and improvements to their husbandry be made on an evidence-based approach. 
We demonstrate that zoo-themed research output is slowly filling in these gaps for more and more species, and we have evaluated how this research can have wider impact across scientific publications with a broader readership (Fig. 2). From the output in Melfi (2009), 89\% of the sample concerned mammals ( $60 \%$ of which was primate-focussed), with $8 \%$ on birds, $1 \%$ on reptiles and $1 \%$ on other taxa. Whilst the Melfi (2009) dataset was restricted to output from only one region (British \& Irish facilities), the bias for investigating mammalian species is clear. Within our main Web of Science $\odot$ dataset, $69 \%$ of papers focussed solely on mammals ( $40 \%$ on primates)- therefore highlighting a shift change towards the use of other species as research subjects that is unrelated to the number of species kept of a given taxa.

Inter-disciplinary research also identifies the usefulness of zoo information to big data questions, and such an approach helps further reduce the lack of biological information as identified by Melfi (2009). Information held in the Zoological Information Management System (ZIMS) database, managed by species360 (species360, 2018) has added to the bank of biological information held on non-domestic species (Conde et al., 2019) to improve our knowledge and understanding of many important areas of species biology, physiology and life history. To develop this research output, zoos should be increasing the number of scientific studies being published within higher impact journals. Our dataset shows that mammals remain considerably better represented in publications than all other taxonomic groups combined. Indeed, two mammalian Orders, Carnivora (154 papers) and Primates (294 papers), are both better represented in research output than all birds, reptiles, amphibians and fish together (204 papers) for papers covering a single taxonomic class.

Publication output centring on a few species within taxonomic groups that are the focus of research attention is documented (Bautista and Pantoja, 2005) and similar reasons are postulated to ones that we cover in our evaluation (i.e., flagship for conservation). These authors also note that fish are an underrepresented group in "wildlife research" and again this echoes our own zoofocussed findings. Given that aquarium-housed fish can be flagships for conservation research, e.g., McGregor Reid et al. (2013), there is the potential to build on key traits that make a specific taxa suitable for scientific study to increase its use for research. Increases in species-specific output may be based on active researchers investigating questions on the same taxa because these are considered the most appropriate for that question. However, scientists could consider diversifying the taxa used to ask a similar question. For example, the use of highly-cognitive birds instead of primates for cognition research, facilitating the use of nonmammalian species. Use of cephalopods to determine personality differences (Carere et al., 2015) can be a realistic alternative to primate studies given the complex cognition of these invertebrates (Mather and Dickel, 2017) that involves both short- and long-term learning and engagement in behaviours such as play.

However, we should also be mindful of the importance of knowledge gaps (e.g., the achievement of optimal welfare) for all captive species, regardless of taxonomic class and therefore zoos should actively engage in directed scientific research to answer key applied questions. A lack of background knowledge on such species, hampering effective evaluation of any results generated, may be causing researchers to choose more familiar species as study models. When considering zoo-specific and open access publications (Fig. S2, Supplementary information) there is an overall predominance of mammalian-research noted, even when annual volumes are themed around a particular taxa, such as freshwater fish (McGregor Reid, 2013), or area of work, such as reintroduction and translocation practice (Gilbert and Soorae, 2017).

The continuing decline in biodiversity is resulting in zoos providing care for species with a limited to non-existent captive history. Science has a role to play in informing practice for these species if species conservation initiatives are to be successful. Zoos and aquariums are unique in their capacity to provide direct conservation action to threatened species across the globe (Michaels et al., 2014, Biega et al., 2019), and it is encouraging to see that many zoo research projects already focus on conservation breeding and the wider role of animals in ecosystem health. Zoo studies currently are used to better inform conservation projects for animals in situ (da Silva et al., 2019, Lacy, 2019) and this trend is likely to continue into the future. The success of in-situ conservation initiatives can be hindered by a lack of evidence (Reichhardt, 1999, Schwartz, 2008) and therefore decisions that influence population management, breeding recommendations and similar measures to conserve biological diversity ex situ must have an evidence basis to them.

The Convention on Biological Diversity (2020) is currently developing a post-2020 global biodiversity framework, which will aim to address the key drivers of extinction (CBD, 2019). A key area for future focus is the relatively poor representation of amphibians, both in zoo collection plans, and also in the research output. Zoos appear to be housing relatively few species of amphibians. In relation to biodiversity and conservation, there are over 7900 amphibian species, and roughly $40 \%$ of these species are threatened with extinction (IUCN, 2019). While some animal collections have produced excellent conservation education strategies centred around amphibians (Pavajeau et al., 2008), it is clear there is room for development of collection plans for these species. It may be difficult for visitors to appreciate the diversity of threatened amphibians if few are represented in captivity (Michaels et al., 2014b).

Because zoological collections have the responsibility of maintaining populations of highly endangered species, prioritising research into areas of population sustainability, educational initiatives and human behaviour change, can help inform the overall conservation plan for species at the brink of extinction. Whilst our results show that current conservation and ecosystem health output appears low, there is evidence that the quantity of research output is growing. This range of publications has value for those engaged in direct conservation action, as well as to educators disseminating information to zoo visitors and beyond.

It is interesting to note that the best represented animals in our dataset also appear to be some of the favourite animals of zoo visitors (Carr 2016). Primates, carnivores and elephants are wellrepresented in the public's top ten favourite animals (Courchamp et al., 2018) and whilst it is beyond the scope of this paper to determine why these animals appear to feature in both public interest and in zoo literature, we do suggest that public interest could act as a driver for research focus on this species (i.e., to better inform practice and scrutinise the extent to which species are presented to visitors). We do not suggest "less primates" in the output from zoos but more focus on other taxa, as well as the continuation of high levels of research on traditional study species. We would encourage researchers to consider their choice of study population carefully and think about other benefits to their research. It might be intriguing to study chimpanzees but is there more added conservation, education and recreational value if the waxy monkey frog (Phyllomedusa sauvagii) was studied instead...?

In conclusion, our results demonstrate that, globally, zoothemed researchers have an impressive scientific output and are investigating a range of empirical, hypothesis-driven questions that relate to all the modern zoo's key roles. Between 2009 and 2018, considerable progress has been made regarding the number of zoo-based publications, especially papers focussed on welfare assessment or improvement. Our results show that there remains a mismatch between the number of species 
within a taxonomic class held in captivity and the representation of this class in the peer-reviewed literature. Whilst it is relevant that some charismatic species are receiving considerable publication interest, further focus on species that are less represented in literature would help the zoological community to develop welfare indicators and evidence-based husbandry more rapidly for a wider range of taxa. The research output of zoological collections is worthwhile, not only for those working within the industry, but also for those working in other capacities with wild animals and in related disciplines (e.g., acade$\mathrm{mia}$ ). As such, progress in increasing the number of questions being posed and output of answering such questions, both within and beyond the zoo, has value to people and animals worldwide.

\section{Data availability}

The dataset on publications gathered from scientific databases is available at Open Research Exeter: https://ore.exeter.ac.uk/ repository/handle/10871/39092. The dataset generated on species holdings are not publicly available due to this project still be researched but are available from author James E. Brereton upon reasonable request.

Received: 25 June 2019; Accepted: 7 October 2019;

Published online: 29 October 2019

\section{References}

Asa CS, Traylor-Holzer K, Lacy RC (2011) Can conservation-breeding programmes be improved by incorporating mate choice? Int Zoo Yearb 45 (1):203-212

Bautista LM, Pantoja JC (2005) What animal species should we study next? Bull Br Ecol Soc 36(4):27-28

Benjamini Y, Hochberg Y (1995) Controlling the false discovery rate: a practical and powerful approach to multiple testing. J R Stat Soc Ser B 57(1):289-300

Bethell EJ (2015) A "How-To" guide for designing judgment bias studies to assess captive animal welfare. J Appl Anim Welf Sci 18:S18-S42

BIAZA (2018a) Helping the less charismatic species. British and Irish Association of Zoos and Aquariums. https://biaza.org.uk/news/detail/helping-the-lesscharasmatic-species. Accessed 27 May 2019

BIAZA (2018b) Research. British and Irish Association of Zoos and Aquariums. https://biaza.org.uk/research. Accessed 25 May 2019

Biega AM, Lamont M, Mooers A, Bowkett AE, Martin TE (2019) Guiding the prioritization of the most endangered and evolutionary distinct birds for new zoo conservation programs. Zoo Biol 38(3):305-315

Bueddefeld JNH, Van Winkle CM (2018) The role of post-visit action resources in facilitating meaningful free-choice learning after a zoo visit. Environ Educ Res 24(1):97-110

Carere C, Grignani G, Bonanni R, Della Gala M, Carlini A, Angeletti D, Cimmaruta R, Nascetti G, Mather JA (2015) Consistent individual differences in the behavioural responsiveness of adult male cuttlefish (Sepia officinalis). Appl Anim Behav Sci 167:89-95

Carere C, Wood JB, Mather J (2011) Species differences in captivity: where are the invertebrates? Trends Ecol Evolution 26(5):211

Carr N (2016) An analysis of zoo visitors' favourite and least favourite animals. Tour Manag Perspect 20:70-76

CBD (2019) The 2020 biodiversity strategic planning timeline. Convention on Biological Diversity. https://post2020.unep-wcmc.org/. Accessed 27 May 2019

CBSG (2015) The One Plan Approach to conservation. IUCN SSC Conservation Breeding Specialist Group. http://www.cbsg.org/our-approach/one-planapproach-conservation. Accessed 27 May 2019

Clubb R, Mason GJ (2003) Animal welfare: captivity effects on wide-ranging carnivores. Nature 425(6957):473-474

Conde DA, Staerk J, Colchero F, da Silva R, Schöley J, Baden HM, Jouvet L, Fa JE, Syed H, Jongejans E, Meiri S, Gaillard J-M, Chamberlain S, Wilcken J, Jones OR, Dahlgren JP, Steiner UK, Bland LM, Gomez-Mestre I, Lebreton J-D, González Vargas I, Flesness N, Canudas-Romo V, Salguero-Gómez R, Byers O, Berg TB, Scheuerlein A, Devillard S, Schigel DS, Ryder OA, Possingham HP, Baudisch A, Vaupel JW (2019) Data gaps and opportunities for comparative and conservation biology. Proc Natl Acad Sci 116 (19):9658-9664
Costa R, Sousa C, Llorente M (2018) Assessment of environmental enrichment for different primate species under low budget: a case study. J Appl Anim Welf Sci 21(2):185-199

Courchamp F, Jaric I, Albert C, Meinard Y, Ripple WJ, Chapron G (2018) The paradoxical extinction of the most charismatic animals. PLoS Biol 16(4): e2003997

da Silva R, Pearce-Kelly P, Zimmerman B, Knott M, Foden W, Conde DA (2019) Assessing the conservation potential of fish and corals in aquariums globally. J Nat Conserv 48:1-11

Dawson E, Jensen E (2011) Towards a contextual turn in visitor studies: evaluating visitor segmentation and identity-related motivations. Visitor Stud 14 (2):127-140

EAZA (2019) Specialist programmes. European association of zoos and aquaria. www.eaza.net/conservation/programmes. Accessed 27 May 2019

Fernandez EJ, Tamborski MA, Pickens SR, Timberlake W (2009) Animal-visitor interactions in the modern zoo: conflicts and interventions. Appl Anim Behav Sci 120(1):1-8

Fernandez EJ, Timberlake W (2008) Mutual benefits of research collaborations between zoos and academic institutions. Zoo Biol 27(6):470-487

Fox J, Weisberg S (2011) An R companion to applied regression. Sage, Thousand Oaks

Gilbert T, Soorae PS (2017) Editorial: the role of zoos and aquariums in reintroductions and other conservation translocations. Int Zoo Yearb 51(1):9-14

Greenwell PJ, Montrose VT (2017) The gray matter: prevention and reduction of abnormal behavior in companion gray parrots (Psittacus erithacus). J Vet Behav 18(1):76-83

Gussek I, Große-Brinkhaus C, Südekum KH, Hummel J (2018) Influence of ration composition on nutritive and digestive variables in captive giraffes (Giraffa camelopardalis) indicating the appropriateness of feeding practice. J Anim Physiol Anim Nutr 102(2):e513-e524

Halekoh U, Højsgaard S (2014) A Kenward-Roger approximation and parametric bootstrap methods for tests in linear mixed models-The R package pbkrtest. J Stat Softw 59(9):1-30

Hatt JM, Schaub D, Wanner M, Wettstein HR, Flach EJ, Tack C, Hässig M, Ortmann S, Hummel J, Clauss M (2005) Energy and fibre intake in a group of captive giraffe (Giraffa camelopardalis) offered increasing amounts of browse. J Vet Med Ser A 52(10):485-490

Hosey GR (1997) Behavioural research in zoos: academic perspectives. Appl Anim Behav Sci 51(3-4):199-207

Hosey GR, Melfi VA, Pankhurst S (2009) Zoo animals: behaviour, management and welfare. Oxford University Press, Oxford, UK

IUCN (2019) Summary statistics. International Union for the Conservation of Nature. https://www.iucnredlist.org/resources/summary-statistics. Accessed 27 May 2019

Jensen E (2010) Learning about animals, science and conservation: Large-scale survey-based evaluation of the educational impact of the ZSL London Zoo Formal Learning programme. Full Report: Large Scale Pupil Survey. ZSL London Zoo, London

Kleiber C, Zeileis A (2008) Applied econometrics with R. Springer-Verlag, New York

Kroshko J, Clubb R, Harper L, Mellor E, Moehrenschlager A, Mason G (2016) Stereotypic route tracing in captive Carnivora is predicted by species-typical home range sizes and hunting styles. Anim Behav 117(1):197-209

Lacy RC (2019) Lessons from 30 years of population viability analysis of wildlife populations. Zoo Biol 38(1):67-77

Lenth RV (2016) Least-squares means: the R package lsmeans. J Stat Softw 69 (1):1-33

Loh T-L, Larson ER, David SR, de Souza LS, Gericke R, Gryzbek M, Kough AS, Willink PW, Knapp CR (2018) Quantifying the contribution of zoos and aquariums to peer-reviewed scientific research. FACETS 3(1):287-299

Marino L, Lilienfeld SO, Malamud R, Nobis N, Broglio R (2010) Do zoos and aquariums promote attitude change in visitors? A critical evaluation of the American zoo and aquarium study. Soc Anim 18(2):126-138

Mason GJ (2010) Species differences in responses to captivity: stress, welfare and the comparative method. Trends Ecol Evol 25(12):713-721

Mason GJ (2015) Using species differences in health and well-being to identify intrinsic risk and protective factors. WAZA Mag 16(1):2-5

Mason P (2007) Roles of the modern zoo: conflicting or complementary? Tour Rev Int 11(3):251-263

Mather JA, Dickel L (2017) Cephalopod complex cognition. Curr Opin Behav Sci 16:131-137

McGregor Reid G (2013) Introduction to freshwater fishes and their conservation. Int Zoo Yearb 47(1):1-5

McGregor Reid G, Contreras MacBeath T, Csatádi K (2013) Global challenges in freshwater-fish conservation related to public aquariums and the aquarium industry. Int Zoo Yearb 47(1):6-45

Mehrkam LR, Dorey NR (2015) Preference assessments in the zoo: Keeper and staff predictions of enrichment preferences across species. Zoo Biol 34(5):418-430 
Melfi VA (2009) There are big gaps in our knowledge, and thus approach, to zoo animal welfare: a case for evidence-based zoo animal management. Zoo Biol 28(6):574-88

Mellor E, McDonald Kinkaid H, Mason G (2018) Phylogenetic comparative methods: harnessing the power of species diversity to investigate welfare issues in captive wild animals. Zoo Biol 37(5):369-388

Michaels CJ, Downie JR, Campbell-Palmer R (2014) The importance of enrichment for advancing amphibian welfare and conservation goals: a review of a neglected topic. Amphibian Reptile Conserv 8(1):7-23

Moss A, Esson M (2010) Visitor interest in zoo animals and the implications for collection planning and zoo education programmes. Zoo Biol 29(6):715-731

Moss A, Esson M (2013) The educational claims of zoos: where do we go from here? Zoo Biol 32(1):13-18

Moss A, Jensen E, Gusset M (2017) Impact of a global biodiversity education campaign on zoo and aquarium visitors. Front Ecol Environ 15(5):243-247

Pagano AM, Carnahan AM, Robbins CT, Owen MA, Batson T, Wagner N, Cutting A, Nicassio-Hiskey N, Hash A, Williams TM (2018) Energetic costs of locomotion in bears: is plantigrade locomotion energetically economical? J Exp Biol 221(12):jeb175372

Pavajeau L, Zippel KC, Gibson R, Johnson K (2008) Amphibian ark and the 2008 year of the frog campaign. Int Zoo Yearb 42(1):24-29

Plowman AB (2003) A note on a modification of the spread of participation index allowing for unequal zones. Appl Anim Behav Sci 83(4):331-336

Plowman AB (2008) BIAZA statistics guidelines: toward a common application of statistical tests for zoo research. Zoo Biol 27(3):226-233

R Core Team (2016) R: A language and environment for statistical computing. $R$ Foundation for Statistical Computing, Vienna, Austria

Reade LS, Waran NK (1996) The modern zoo: how do people perceive zoo animals? Appl Anim Behav Sci 47(1):109-118

Reichhardt T (1999) Inadequate science'in US habitat plans. Nature 397:287

Richter SH, Hintze S (2019) From the individual to the population-and back again? Emphasising the role of the individual in animal welfare science. Appl Anim Behav Sci 212(1):1-8

Rose PE (2018) Ensuring a good quality of life in the zoo. Underpinning welfarepositive animal management with ecological evidence. In: Berger M, Corbett S (eds) Zoo animals: behavior, welfare and public interactions. Nova Science Publishers Inc, New York

Rose PE, Brereton JE, Gardner L (2016) Developing flamingo husbandry practices through workshop communication. J Zoo Aquar Res 4(2):115-121

Roth TL, Bateman HL, Kroll JL, Steinetz BG, Reinhart PR (2004) Endocrine and ultrasonographic characterization of a successful pregnancy in a Sumatran rhinoceros (Dicerorhinus sumatrensis) supplemented with a synthetic progestin. Zoo Biol 23(3):219-238

Rowden LJ, Rose PE (2016) A global survey of banteng (Bos javanicus) housing and husbandry. Zoo Biol 35(6):546-555

Schwartz MW (2008) The performance of the endangered species act. Annu Rev Ecol, Evolution, Syst 39:279-299

Singmann H, Bolker B, Westfall J, Aust F (2019) afex: Analysis of Factorial Experiments. $\mathrm{R}$ package version 0.23-0. https://CRAN.R-project.org/ package $=$ afex.

Smith LM, Broad S, Weiler B (2008) A closer examination of the impact of zoo visits on visitor behaviour. J Sustain Tour 16(5):544-562

species360 (2018) Data science for zoos and aquariums. species360. https://www. species360.org/products-services/zoo-aquarium-animal-managementsoftware/. Accessed 27 May 2019

Spooner SL, Jensen EA, Tracey L, Marshall AR (2019) Evaluating the impacts of theatre-based wildlife and conservation education at the zoo. Environ Educ Res. https://doi.org/10.1080/13504622.2019.1569201(0)

Sutherland WJ (1998) The importance of behavioural studies in conservation biology. Anim Behav 56(4):801-809

Tonkins BM, Tyers AM, Cooke GM (2015) Cuttlefish in captivity: an investigation into housing and husbandry for improving welfare. Appl Anim Behav Sci 168:77-83

Traylor-Holzer K, Leus K, Bauman K (2019) Integrated Collection Assessment and Planning (ICAP) workshop: Helping zoos move toward the One Plan Approach. Zoo Biol 38(1):95-105
Troxell-Smith SM, Watters JV, Whelan CJ, Brown JS (2017a) Zoo foraging ecology: Preference and welfare assessment of two okapi (Okapia johnstoni) at the Brookfield Zoo. Anim Behav Cognition 4(2):187-199

Troxell-Smith SM, Whelan CJ, Magle SB, Brown JS (2017b) Zoo foraging ecology: development and assessment of a welfare tool for captive animals. Anim Welf 26(3):265-275

Venables WN, Ripley BD (2002) Modern applied statistics with S. Springer, New York

Wagoner B, Jensen E (2010) Science learning at the zoo: evaluating children's developing understanding of animals and their habitats. Psychol Soc 3 (1):65-76

Whitham JC, Wielebnowski N (2013) New directions for zoo animal welfare science. Appl Anim Behav Sci 147(3-4):247-260

Williams E, Chadwick Cl, Yon L, Asher L (2018) A review of current indicators of welfare in captive elephants (Loxodonta africana and Elephas maximus). Anim Welf 27(3):235-249

Yon L, Williams E, Harvey ND, Asher L (2019) Development of a behavioural welfare assessment tool for routine use with captive elephants. PLoS ONE 14 (2): $\mathrm{e} 0210783$

Zippel K, Johnson K, Gagliardo R, Gibson R, McFadden M, Browne RK, Martinez C, Townsend E (2011) The Amphibian Ark: a global community for ex situ conservation of amphibians. Herpetol Conserv Biol 6(3):340-352

\section{Acknowledgements}

We thank A. Loader for her help with compiling data from JZAR and the IZYB. We thank S. Bereton for assistance with the global species holdings dataset. The open access publication charge was covered by the University of Exeter's Institutional APC Fund.

\section{Author contributions}

All authors contributed to data collection for and writing of the paper, under the direction of the corresponding author.

\section{Competing interests}

The authors declare no competing interests.

\section{Additional information}

Supplementary information is available for this paper at https://doi.org/10.1057/s41599 019-0345-3.

Correspondence and requests for materials should be addressed to P.E.R.

Reprints and permission information is available at http://www.nature.com/reprints

Publisher's note Springer Nature remains neutral with regard to jurisdictional claims in published maps and institutional affiliations.

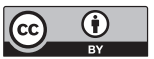

Open Access This article is licensed under a Creative Common Attribution 4.0 International License, which permits use, sharing, adaptation, distribution and reproduction in any medium or format, as long as you give appropriate credit to the original author(s) and the source, provide a link to the Creative Commons license, and indicate if changes were made. The images or other third party material in this article are included in the article's Creative Commons license, unless indicated otherwise in a credit line to the material. If material is not included in the article's Creative Commons license and your intended use is not permitted by statutory regulation or exceeds the permitted use, you will need to obtain permission directly from the copyright holder. To view a copy of this license, visit http://creativecommons.org/ licenses/by/4.0/

(C) The Author(s) 2019 